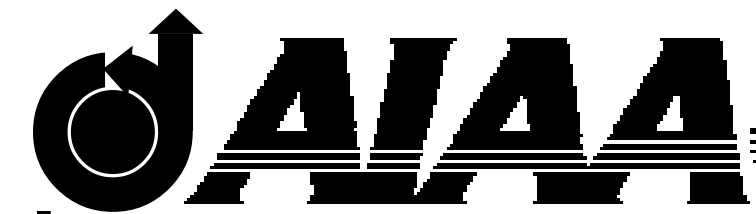

\title{
AIAA 96-4245 Analysis of Shuttle Orbiter Reliability and Maintainability Data for Conceptual Studies
}

W. D. Morris

N. H. White

NASA Langley Research Center Hampton, Virginia

Dr. C. E. Ebeling

University of Dayton

Dayton, Ohio

1996 AIAA Space Programs and Technologies Conference September 24-26, 1996/Huntsville, AL 


\title{
ANALYSIS OF SHUTTLE ORBITER RELIABILITY AND MAINTAINABILITY DATA FOR CONCEPTUAL STUDIES
}

\author{
W. D. Morris*, N. H. White** \\ NASA Langley Research Center \\ Hampton, Virginia \\ Dr. C. E. Ebeling † \\ University of Dayton \\ Dayton, Ohio
}

\begin{abstract}
In order to provide a basis for estimating the expected support required of new systems during their conceptual design phase, Langley Research Center has recently collected Shuttle Orbiter reliability and maintainability data from the various data base sources at Kennedy Space Center. This information was analyzed to provide benchmarks, trends, and distributions to aid in the analysis of new designs. This paper presents a summation of those results and an initial interpretation of the findings.

\section{NOMENCLATURE}

$\begin{array}{ll}\text { APU } & \text { Auxilary Power Unit } \\ \text { COMM } & \text { Communications } \\ \text { ECLS } & \text { Environmental Control and Life Support } \\ \text { EXP } & \text { Exponential } \\ \text { FPOT } & \text { Flight Power On Time } \\ \text { GPOT } & \text { Ground Power On Time } \\ \text { IOS } & \text { Integrated Operations System } \\ \text { IWCS } & \text { Integrated Work Control System } \\ \text { HC } & \text { Head Count } \\ \text { KSC } & \text { Kennedy Space Center } \\ \text { LaRC } & \text { Langley Research Center } \\ \text { LOG } & \text { Lognormal } \\ \text { LSTAR } & \text { Launch + 15 Day Shuttle Trend Analysis } \\ & \text { Report } \\ \text { MHRS } & \text { Manhours } \\ \text { MAINT } & \text { Maintence } \\ \text { MTAR } & \text { Maintenance Trend Analysis Report }\end{array}$
\end{abstract}

*Aerospace Technologist, Space Systems and Concepts Division, Member AIAA.

**Aerospace Technologist, Space Systems and

Concepts Division.

$\dagger$ Associate Professor, School of Engineering. Copyright $\odot$ American Institute of Aeronautics and Astronautics, Inc. No copyright is asserted in the United States under Title 17, U.S. Code. The U.S. Government has a royalty-free license to exercise all rights under the copyright claimed herein for Governmental Purposes. All other rights are reserved by the copyright owner.
MTBMA Mean Time Between Maintenance Actions

MTTR Mean Time To Repair

OMDP Orbiter Maintenance Down Period

PRACA Problem Reporting and Corrective Action

PV\&D Purge Vent \& Drain

R\&M Reliability and Maintainability

RCM Reliability Centered Maintenance

RCS Reaction Control System

SFC/DC Shop Floor Control/Data Collection

SPDMS Shuttle Processing Data Management System

STS Space Transportation System

TCS Thermal Control System

TPS Thermal Protection System

TVC Thrust Vector Control

WEIB Weibull

\section{INTRODUCTION}

One of the best guides for estimating future performance of conceptual systems is current experience with similar systems. For those charged with assessing the support required of future reusable launch systems, the experience base is the Shuttle Orbiter. However, the lack of a suitable compilation of the reliability and maintainability (R\&M) history of the Orbiter has been a major hindrance in benefiting from that experience. Such information is needed by those working in space operations who are charged with the responsibility of both assessing the support required of future systems and of identifying the benefits of developing new technologies for support of those systems. This information is used to help establish rational levels of support for a new generation of vehicles that are traceable to current flight experience and to help evaluate the value of new technologies in reducing both the time and cost to operate a new system.

The analysis of aircraft support has used historical $\mathrm{R} \& \mathrm{M}$ data from operational systems in combination with 
simulation models to define and improve the effectiveness of their support systems for over 25 years ${ }^{1}$. Early work defining support for conceptual launch vehicles also attempted to use this approach with discrete event simulation modeling 2-4. Although useful for launch vehicles in giving general insight to support requirements, the models had to be based on assumed parametric values such as turnaround time, manpower, number of facilities, etc., since historically defined support requirements were generally only available at highly aggregated levels. This level lacked the fidelity necessary to evaluate the effects of introducing new technologies or procedures. For conceptual studies, the modeler is in need of information on the type, frequency and duration of tasks, along with the crew sizes required for support of new launch systems. One of the initial data studies which collected Shuttle support information was specifically designed to aid in the process definition and to define manpower and task times for launch operations ${ }^{5}$. While information from this study aided simulation modeling, it lacked completeness and contained insufficient data to statistically characterize the results.

Lacking good R\&M histories on Shuttle, aircraft data has been used to formulate an analysis tool based on parametric estimating relationships ${ }^{6-8}$. This method built on one developed by Weber ${ }^{9}$ for analyzing space system designs using aircraft data. As Shuttle data became available in the post Challenger time period, a study by Martin Marietta ${ }^{10}$ was initiated to define $R \& M$ data from the Shuttle program that was comparable to the aircraft data used by this analysis model. The study provided Shuttle data similar to the aircraft reliability histories, but required major assumptions to develop the maintainability data. A more recent study has confirmed that the maintainability data is not available from the existing Shuttle electronic databases ${ }^{11}$ at a fidelity comparable to aircraft databases.

A number of working reports are now being issued to aid those responsible for Shuttle processing. Typical are the MTAR (Maintenance Trend Analysis Report ${ }^{12}$ ), LSTAR (Launch + 15 Day Shuttle Trend Analysis Report Plus $^{13}$ ) and RCM (Reliability-Centered Maintenance ${ }^{14}$ ) reports. The focus of each is on slightly different aspects of the support. Although these reports contain useful modeling information, their emphasis is on process control and are intended to highlight current and emerging problem areas to management attention so that they can be addressed in a timely manner. They do not provide the modeler all of the information nor offer the longer historical perspective needed for use in conceptual studies.
All of these reports are drawn from data contained in the Kennedy Space Center (KSC) data bases. However, none of the cited reports provide a linkage between the problems that initiated maintenance actions and the support manpower and time required to analyze and/or correct it. This is of primary interest for modeling these activities for future launch systems. The recent implementation of the Integrated Work Control System (IWCS) as a part of Shuttle Processing Data Management System (SPDMS) provided the opportunity to define that connection. The Langley Research Center (LaRC) initiated a study by Lockheed Martin Advanced Programs Group ${ }^{15}$ at KSC to update the data base that had been developed in $1992^{10}$ and to collect this additional information on maintenance activities which had not been available at the time of the earlier report. The results from this most recent study form the basis of this report. This paper will examine the Shuttle R\&M data to identify characteristics and trends consistent with this phase of the program. In particular, it will attempt to provide insight to the manpower and repair time characteristics of the Shuttle's support concept that can be used for modeling the support requirements of future reusable launch vehicles.

\section{SCOPE/METHODS/APPROACH}

Ideally, a complete and detailed component level $\mathrm{R} \& \mathrm{M}$ history would be available for the Shuttle Orbiter, comparable to that available for military aircraft. That level of information, however, is simply not available for Shuttle systems. This study made use of current data collection systems in-place at KSC to collect and analyze information which would be consistent with the level of analysis used in Langley's conceptual studies. Typically, these studies are conducted at the subsystem level. Since these studies are frequently addressing generic technologies and broad-based processing issues, the application of these techniques at the subsystem level is both appropriate and adequate.

The data base presented in this report consists of data records from post-Challenger flights only for the Shuttle Orbiter. Because the focus was on support of reusable elements, the solid rocket motor and external tank data are not shown as a part of this report. The records presented in this paper reflect tasks required for hands-on support of Orbiter processing between flights. It links planned and unplanned work to both the time and workforce required to perform the task. A total of 29 post-Challenger flights are included in the data base and represent over 75,000 support tasks performed over a 4-year period. 
The operations processing data maintained at KSC was originally driven by the need to track the status and completion of work. Stand alone data systems were typical until a unified electronic data collection system, the SPDMS II, was implemented after the Challenger accident. IWCS was the latest part of the evolution of this system. In addition to better integrating the standalone systems, the IWCS also provided new software functions that allowed for the first time a limited definition of maintenance requirements based on the historical records. The systems which make up IWCS are the primary source of processing data for this study. These were the Integrated Operating System (IOS), the Shop Floor Control /Data Collection (SFC/DC), and the Problem Reporting and Corrective Action (PRACA) data systems (Figure 1).

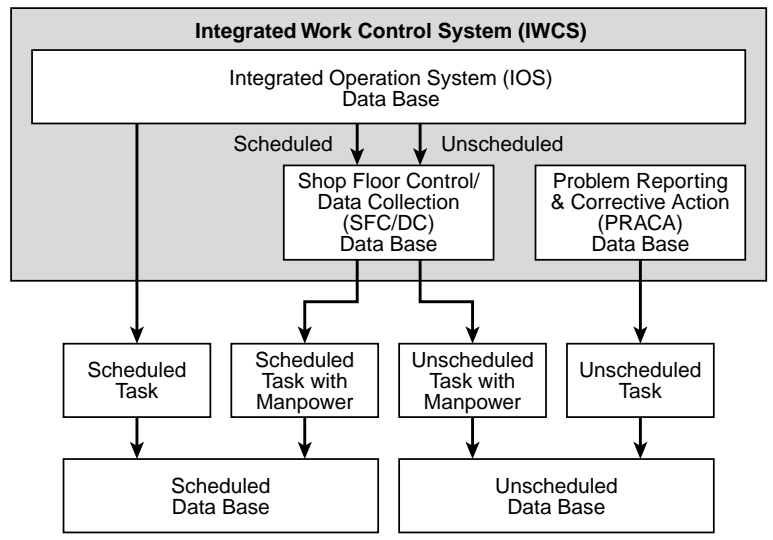

Figure 1. Data base development.

The IOS was used to define both the standard and non-standard tasks for the data base. The standard tasks are frequently referred to as planned or scheduled work. They consists of the Operations and Maintenance Instruction, Repetitive Operations and Maintenance Instruction, Job Card, Work Authorization and the Test Preparation Sheet tasks. The workforce and task time requirements were defined in SFC/DC system for many of the planned tasks identified in the IOS data base. The non-standard or unscheduled tasks were identified in the PRACA data base. These included the Interim Problem Reports, the Problem Reports, and the Discrepancy Reports. Since the PRACA data base does not contain manpower or task time information, it was necessary to use the IOS to identify the corresponding maintenance records in the SFC/ DC data base. Also, because the SFC/DC has been phased into use only in recent years, matching records do not exist for every maintenance action identified in the PRACA data base. For that reason, it became necessary to define the unplanned data from the two different sources. The PRACA data base was used to define the number of maintenance actions and thus the reliability of each subsystem for the purpose of maintenance. The SFC/DC system was used to define the number of people and the time required to perform repair tasks which are then assumed representative of unscheduled maintenance tasks on each subsystem. In a similar fashion, matching records do not exist for every scheduled maintenance task identified in the IOS data base. For that reason, the IOS data base was used to define the number of scheduled tasks and the SFC/DC system was used to define the people and the time required to perform those tasks. Again, these are assumed representative of the scheduled tasks for each subsystem.

Table 1. STS Missions Contained in the R\&M Data Base.

\begin{tabular}{|c|c|c|c|c|}
\hline STS\# & Mission\# & Orbiter & Launch Date & Landing Date \\
\hline 50 & 48 & 102 & $6 / 25 / 92$ & $7 / 9 / 92$ \\
\hline 46 & 49 & 104 & $7 / 31 / 92$ & $8 / 8 / 92$ \\
\hline 47 & 50 & 105 & $9 / 12 / 92$ & 9/20/92 \\
\hline 52 & 51 & 102 & $10 / 22 / 92$ & $11 / 1 / 92$ \\
\hline 53 & 52 & 103 & $12 / 2 / 92$ & $12 / 9 / 92$ \\
\hline 54 & 53 & 105 & $1 / 13 / 93$ & $1 / 19 / 93$ \\
\hline 56 & 54 & 103 & $4 / 8 / 93$ & $4 / 17 / 93$ \\
\hline 55 & 55 & 102 & $4 / 26 / 93$ & $5 / 6 / 93$ \\
\hline 57 & 56 & 105 & $6 / 21 / 93$ & $7 / 1 / 93$ \\
\hline 51 & 57 & 103 & $9 / 12 / 93$ & $9 / 22 / 93$ \\
\hline 58 & 58 & 102 & $10 / 18 / 93$ & $11 / 1 / 93$ \\
\hline 61 & 59 & 105 & 12/2/93 & $12 / 13 / 93$ \\
\hline 60 & 60 & 103 & 2/3/94 & 2/11/94 \\
\hline 62 & 61 & 102 & $3 / 4 / 94$ & $3 / 18 / 94$ \\
\hline 59 & 62 & 105 & $4 / 9 / 94$ & $4 / 20 / 94$ \\
\hline 65 & 63 & 102 & $7 / 8 / 94$ & $7 / 23 / 94$ \\
\hline 64 & 64 & 103 & $9 / 9 / 94$ & $9 / 20 / 94$ \\
\hline 68 & 65 & 105 & $9 / 30 / 94$ & $10 / 11 / 94$ \\
\hline 66 & 66 & 104 & $11 / 3 / 94$ & $11 / 14 / 94$ \\
\hline 63 & 67 & 103 & 2/3/95 & 2/11/95 \\
\hline 67 & 68 & 105 & $3 / 2 / 95$ & 3/18/95 \\
\hline 71 & 69 & 104 & $6 / 27 / 95$ & 7/7/95 \\
\hline 70 & 70 & 103 & 7/13/95 & 7/22/95 \\
\hline 69 & 71 & 105 & 9/7/95 & 9/18/95 \\
\hline 73 & 72 & 102 & $10 / 20 / 95$ & $11 / 5 / 95$ \\
\hline 74 & 73 & 104 & $11 / 12 / 95$ & $11 / 20 / 95$ \\
\hline 72 & 74 & 105 & 1/11/96 & $1 / 20 / 96$ \\
\hline 75 & 75 & 102 & 2/22/96 & $3 / 9 / 96$ \\
\hline 76 & 76 & 104 & $3 / 22 / 96$ & $3 / 31 / 96$ \\
\hline
\end{tabular}

Note: shaded flights not included in this analysis 
Table 2. Benchmark R\&M Results for Shuttle Subsystems.

\begin{tabular}{|c|c|c|c|c|c|c|c|c|c|c|}
\hline \multirow[b]{2}{*}{ Subsys } & \multirow[b]{2}{*}{ Subsys Definition } & \multicolumn{4}{|c|}{ Scheduled } & \multicolumn{5}{|c|}{ Unscheduled } \\
\hline & & $\begin{array}{c}\text { Number } \\
\text { Tasks }\end{array}$ & $\begin{array}{c}\text { Task Time } \\
\text { Hours }\end{array}$ & $\begin{array}{l}\text { Maint. } \\
\text { Mhrs }\end{array}$ & $\begin{array}{c}\text { Crew Size } \\
\text { HC }\end{array}$ & $\begin{array}{c}\text { Maint. } \\
\text { Activities }\end{array}$ & $\begin{array}{l}\text { MTTR } \\
\text { Hours }\end{array}$ & $\begin{array}{l}\text { Maint. } \\
\text { Mhrs }\end{array}$ & $\begin{array}{c}\text { Crew Size } \\
\text { HC }\end{array}$ & $\begin{array}{c}\text { Removal } \\
\text { Rate }\end{array}$ \\
\hline 4 & Structures and thermal control & 0.4 & 17.9 & 45.6 & 2.2 & 0.5 & 9.9 & 15.9 & 1.6 & $20.0 \%$ \\
\hline 5 & Purge, vent and drain & 25.8 & 23.8 & 31.5 & 1.3 & 20.7 & 9.6 & 13.6 & 1.3 & $44.0 \%$ \\
\hline 6 & Thermal control system & 33.0 & 29.5 & 50.7 & 1.7 & 35.1 & 6.1 & 9.2 & 1.5 & $60.6 \%$ \\
\hline 7 & Thermal/aerodynamics & 1.2 & 13.7 & 19.7 & 1.2 & 0.2 & 20.6 & 20.6 & 1.0 & $0.0 \%$ \\
\hline 8 & Structural dynamics/structures & 9.7 & 18.8 & 43.0 & 2.4 & 27.6 & 37.7 & 58.3 & 1.4 & $35.9 \%$ \\
\hline 9 & Thermal protection system (general) & 31.6 & 34.7 & 71.1 & 2.0 & 76.5 & 16.1 & 37.4 & 2.3 & $13.1 \%$ \\
\hline 10 & Wing (general) & 0.5 & 5.4 & 10.8 & 2.0 & 1.2 & 7.6 & 7.6 & 1.0 & $4.4 \%$ \\
\hline 11 & Wing leading edge & 1.2 & 13.6 & 27.9 & 2.0 & 4.1 & 29.8 & 47.1 & 1.5 & $25.9 \%$ \\
\hline 12 & Wing box & 14.7 & 9.0 & 16.1 & 1.8 & 1.6 & 20.1 & 29.3 & 1.5 & $18.8 \%$ \\
\hline 13 & Elevons & 8.8 & 6.2 & 11.1 & 1.7 & 3.9 & 12.9 & 18.1 & 1.3 & $29.9 \%$ \\
\hline 16 & Wing TCS & No Data & & & & 0.4 & 17.6 & 35.2 & 2.0 & $14.3 \%$ \\
\hline 19 & Wing TPS & 171.5 & 12.3 & 22.8 & 1.9 & 375.1 & 15.4 & 23.0 & 1.5 & $28.0 \%$ \\
\hline 20 & Vertical stabilizer (general) & No Data & & & & No Data & & & & \\
\hline 21 & Vertical stabilizer leading edge & 3.2 & 7.6 & 8.3 & 1.1 & No Data & & & & \\
\hline 22 & Vertical fin & 14.5 & 17.4 & 21.3 & 1.2 & 1.9 & 16.5 & 18.0 & 1.1 & $18.4 \%$ \\
\hline 23 & Rudder/speed brake & 2.4 & 8.9 & 11.0 & 1.2 & 5.1 & 47.9 & 57.4 & 1.2 & $23.8 \%$ \\
\hline 26 & Vertical stabilizer TCS & No Data & & & & No Data & & & & \\
\hline 29 & Vertical stabilizer TPS & 1.0 & 7.3 & 7.3 & 1.0 & 58.2 & 11.7 & 12.3 & 1.0 & $21.3 \%$ \\
\hline 30 & Fuselage (general) & 1.5 & 50.0 & 87.1 & 1.7 & No Data & & & & \\
\hline 31 & Fuselage, upper forward & 6.0 & 76.6 & 134.8 & 1.7 & 4.7 & 19.1 & 28.6 & 1.4 & $22.3 \%$ \\
\hline 32 & Fuselage, lower forward & 15.4 & 13.6 & 17.3 & 1.1 & 3.0 & 18.6 & 26.1 & 1.3 & $23.7 \%$ \\
\hline 33 & Crew module & 59.8 & 9.7 & 17.0 & 1.8 & 19.3 & 15.0 & 19.8 & 1.3 & $19.4 \%$ \\
\hline 34 & Fuselage, mid & 39.4 & 17.1 & 34.7 & 2.0 & 14.2 & 17.8 & 29.9 & 1.6 & $19.4 \%$ \\
\hline 35 & Fuselage, aft & 83.3 & 20.1 & 32.9 & 1.6 & 48.0 & 18.4 & 22.4 & 1.2 & $22.0 \%$ \\
\hline 36 & Fuselage TCS & No Data & & & & 10.8 & 13.8 & 20.8 & 1.4 & $31.9 \%$ \\
\hline 37 & Payload bay doors & 25.4 & 11.9 & 39.8 & 3.3 & 7.5 & 23.5 & 32.7 & 1.4 & $14.1 \%$ \\
\hline 38 & Fuselage PV\&D & No Data & & & & 56.2 & 24.5 & 26.8 & 1.2 & $18.5 \%$ \\
\hline 39 & Fuselage TPS & 5.0 & No Data & & & 722.0 & 20.4 & 25.8 & 1.2 & $17.2 \%$ \\
\hline 40 & Propulsion/pwr (general) & 0.9 & 20.8 & 32.9 & 2.5 & No Data & 5.2 & 6.0 & 1.3 & No Data \\
\hline 41 & Main propulsion & 175.7 & 19.5 & 38.7 & 2.0 & 85.2 & 13.8 & 16.5 & 1.2 & $31.8 \%$ \\
\hline 42 & Reaction control/TVC & 57.0 & 35.3 & 44.6 & 1.3 & 21.9 & 16.4 & 22.2 & 1.2 & $37.5 \%$ \\
\hline 43 & Orbiter maneuvering & 110.7 & 25.1 & 38.9 & 1.6 & 23.3 & 11.2 & 13.5 & 1.2 & $25.8 \%$ \\
\hline 45 & Electrical power generation & 16.6 & 38.8 & 73.9 & 1.9 & 7.4 & 9.9 & 11.9 & 1.2 & $46.6 \%$ \\
\hline 46 & Auxiliary power unit & 12.5 & 47.3 & 68.0 & 1.4 & 18.0 & 20.5 & 25.0 & 1.2 & $49.7 \%$ \\
\hline 51 & Landing gear & 47.4 & 41.3 & 93.1 & 2.2 & 9.0 & 10.1 & 18.3 & 1.6 & $26.7 \%$ \\
\hline 52 & Brake/skid control & 6.2 & 15.0 & 23.9 & 1.5 & 1.95 & 12.0 & 16.5 & 1.4 & $41.0 \%$ \\
\hline 53 & Docking mechanism & No Data & & & & 1.15 & 0.6 & 1.3 & 2.0 & $13.0 \%$ \\
\hline 54 & Payload retention/deployment & 15.3 & 26.4 & 72.2 & 2.8 & 2.9 & 12.4 & 21.3 & 1.9 & $31.6 \%$ \\
\hline 55 & Pyrotechnics and range safety & 34.8 & 20.3 & 33.8 & 1.7 & 10.8 & 9.2 & 10.9 & 1.2 & $50.7 \%$ \\
\hline 56 & Attachment/separation & 18.6 & 14.1 & 17.3 & 1.3 & 20.3 & 21.2 & 23.0 & 1.1 & $52.7 \%$ \\
\hline 57 & Aero surface control & 0.2 & 6.3 & 9.1 & 1.5 & 2.8 & 15.6 & 15.8 & 1.0 & $12.5 \%$ \\
\hline 58 & Hydraulics & 8.7 & 51.3 & 72.2 & 1.4 & 26.7 & 12.8 & 16.0 & 1.2 & $41.4 \%$ \\
\hline 59 & Actuation mechanisms & 6.6 & 11.5 & 16.4 & 1.5 & 6.1 & 19.7 & 27.8 & 1.4 & $29.5 \%$ \\
\hline 60 & ECLS (general) & 5.5 & 42.3 & 61.9 & 1.5 & No Data & 9.0 & 12.9 & 1.4 & No Data \\
\hline 61 & Atmospheric revitilization & 9.4 & 14.2 & 19.5 & 1.3 & 7.2 & 16.7 & 21.9 & 1.3 & $34.3 \%$ \\
\hline 62 & port & 7.3 & 22.2 & 30.3 & 1.4 & 7.7 & 15.7 & 19.7 & 1.1 & $39.9 \%$ \\
\hline 63 & Active thermal control & 14.2 & 12.7 & 20.1 & 1.6 & 17.2 & 26.0 & 37.7 & 1.7 & $18.4 \%$ \\
\hline 64 & Airlock support & 2.3 & 25.7 & 35.1 & 1.4 & 1.9 & 12.7 & 14.4 & 1.2 & $26.3 \%$ \\
\hline 65 & Crew provisions & 2.0 & 2.5 & 2.9 & 1.2 & 3.1 & 17.2 & 19.3 & 1.1 & $44.7 \%$ \\
\hline 66 & Crew equipment & 39.2 & 23.5 & 53.4 & 2.3 & 37.7 & 9.6 & 13.2 & 1.4 & $65.2 \%$ \\
\hline 70 & Avionics (general) & 0.2 & 31.2 & 43.7 & 1.2 & 0.5 & 0.6 & 0.6 & 1.0 & $30.0 \%$ \\
\hline 71 & Guidance and navigation & 8.3 & 11.0 & 14.8 & 1.3 & 3.1 & 15.6 & 18.8 & 1.2 & $64.5 \%$ \\
\hline 72 & Data processing & 10.7 & 18.8 & 24.1 & 1.3 & 5.3 & 13.8 & 17.0 & 1.2 & $80.0 \%$ \\
\hline 73 & Displays and controls & 11.0 & 10.7 & 13.1 & 1.2 & 16.3 & 14.8 & 17.9 & 1.2 & $76.6 \%$ \\
\hline 74 & Communications and tracking & 28.5 & 13.2 & 24.4 & 1.8 & 8.8 & 9.9 & 13.2 & 1.4 & $52.0 \%$ \\
\hline 75 & Instrumentation (operational) & 44.2 & 11.1 & 22.8 & 2.1 & 24.1 & 15.9 & 19.7 & 1.2 & $53.6 \%$ \\
\hline 76 & Electrical power distribution & 24.0 & 11.1 & 21.3 & 1.9 & 7.0 & 17.3 & 20.2 & 1.2 & $66.4 \%$ \\
\hline 77 & Interconnecting wiring & 2.4 & 26.6 & 57.5 & 1.8 & 52.6 & 13.6 & 15.8 & 1.2 & $19.1 \%$ \\
\hline 78 & Instrumentation development & 1.6 & 16.3 & 24.7 & 1.5 & 0.3 & 42.4 & 46.3 & 1.1 & $50.0 \%$ \\
\hline 79 & Flight control & 5.1 & 13.3 & 23.7 & 1.7 & 2.8 & 14.1 & 17.4 & 1.2 & $38.9 \%$ \\
\hline
\end{tabular}

Mean operating time: GPOT $=1,450$ hours; FPOT $=264$ hours 
The data base presented in this report (Table 1) is drawn from the initial 29 flights minus: the Orbiter Maintenance Down Period (OMDP) flights (STS-53, 66, 73) which were not representative of normal processing; several of the early flights where data collection was initially being implemented (STS-50, 46,47,52); and the last two flights for which all data may not have been available at the time it was downloaded (STS-75, 76). Results for the 20 flights that were included were summarized in terms of the scheduled and unscheduled work required for support for each of the Shuttle's subsystems. These values weighted by the number of tasks are presented as a characterization of the R\&M parameters that could be expected using Shuttle technologies for typical missions of similar environments and duration. Representative ground and flight operating hours were developed as a part of the study to be used for defining the maintenance failure rate (Table 2). These rates are not computed here, leaving to the analyst to decide whether the operating hours or some other parameter is the appropriate reliability metric for their study. In addition, histograms were developed for each task to describe the variability in processing time and workforce representative of the task. These were also examined over the 4-year period for trends.

\section{RESULTS \& DISCUSSION}

\section{Summary Results}

A summary of the results are presented in Table 2 for selected Shuttle subsystems. These characteristics are the mean number of scheduled tasks and the mean time and crew size required per task weighted by the number of tasks. Also shown are the mean number of unscheduled maintenance actions for each subsystem along with the mean time to repair and crew sizes used. The removal rate is based on the disposition code for each maintenance action and is also a weighted mean. All results are based on the flight subsystem codes as defined in reference 16. Subsystems that were excluded are those that were not representative of reusable elements such as the external tank, or subsystem codes that describe unique systems such as orbiter experiments or mission kits.

The results are intended to be representative of the frequency of task, the time required and the number of personnel required for touch labor associated with each subsystem. An implicit assumption is made that the type of failures that occur and the time and manpower required for support can be used to uniquely characterize each subsystem code. For example, to maintain a hydraulic system using the same maintenance concept as Shuttle would require 8.7 tasks after each flight using sufficient personnel to average a crew size of 1.4 working 51.3 hours on each task. In addition, the number of unscheduled maintenance actions that could be expected for a new system flying a similar technology in the same flight environment would be 26.7. An average crew of 1.2 could perform repair in 12.8 hours for each maintenance action required. These task/repair times are based on the assumption that the data collected from the SFC/DC were representative of all tasks for each subsystem. Accounting for new technology, changes in the operating environment, or alternate processing procedures for future launch systems would be accomplished by the modeler based on these benchmark values.

Not all scheduled tasks could be identified by subsystem code in the IOS data base, resulting in an underestimate of the total number of tasks required. The task/ repair times presented here represent the time from task assignment to close-out including accessing, diagnosing, and some short term delays. Delays that were coded into the shop floor data have been excluded from the serial time required for the task. The original data records contained some tasks that were never closed. These were assumed to be procedural errors and a task time of 12 hours was assigned to these. This is the longest a technician could typically work in a day even with overtime. It should be noted that the Main Propulsion subsystem data generally includes only the work required to remove and replace the engines after each flight. The actual engine repair work is accomplished in a repair shop which is not a part of the SFC system. That data was not available for this study. It also must be noted that no data entry against a subsystem does not necessarily indicate that no work was required. Since the data system has been phased in, work may have been accomplished before the data system was instituted. Also since the number of tasks are from a different data base than the one in which the maintenance work was defined, a certain amount of inconsistency is inevitable. In addition, it appears that the assignment of the subsystem to the work performed could be done independently in the various data bases, so at times this identification was redefined to different subsystems.

Several subsystems were selected to be representative of different types of support: thermal protection, propulsion, power, hydraulics, avionics and electrical. The data for each were examined for any observable trends over the time period covered by the data and for distribu- 

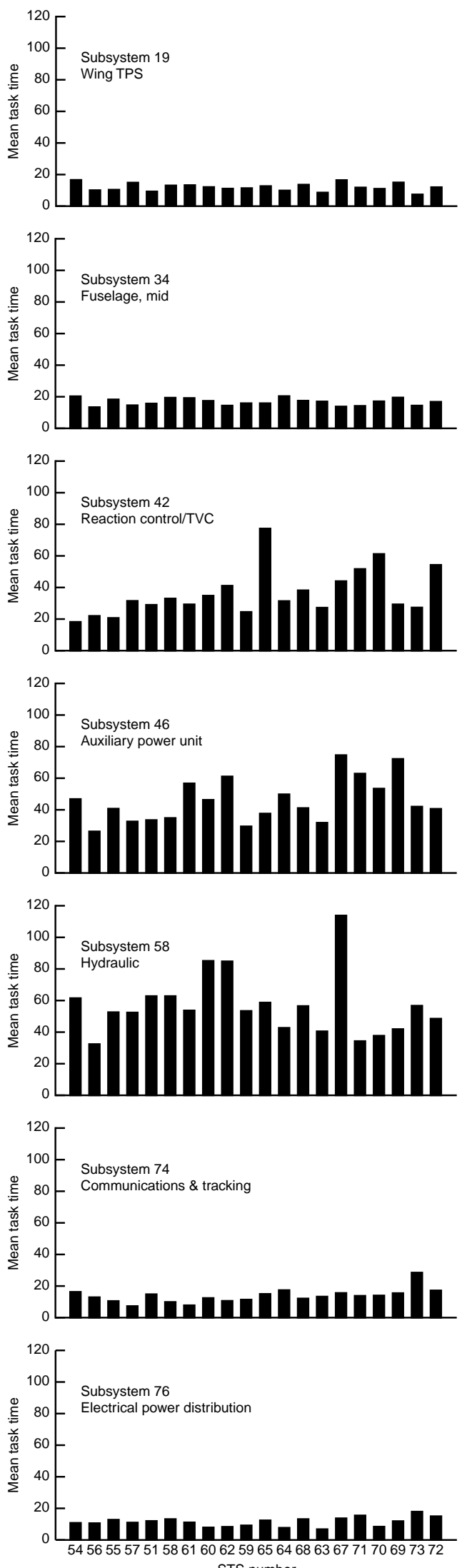

Figure 2. Scheduled mean task time per mission.
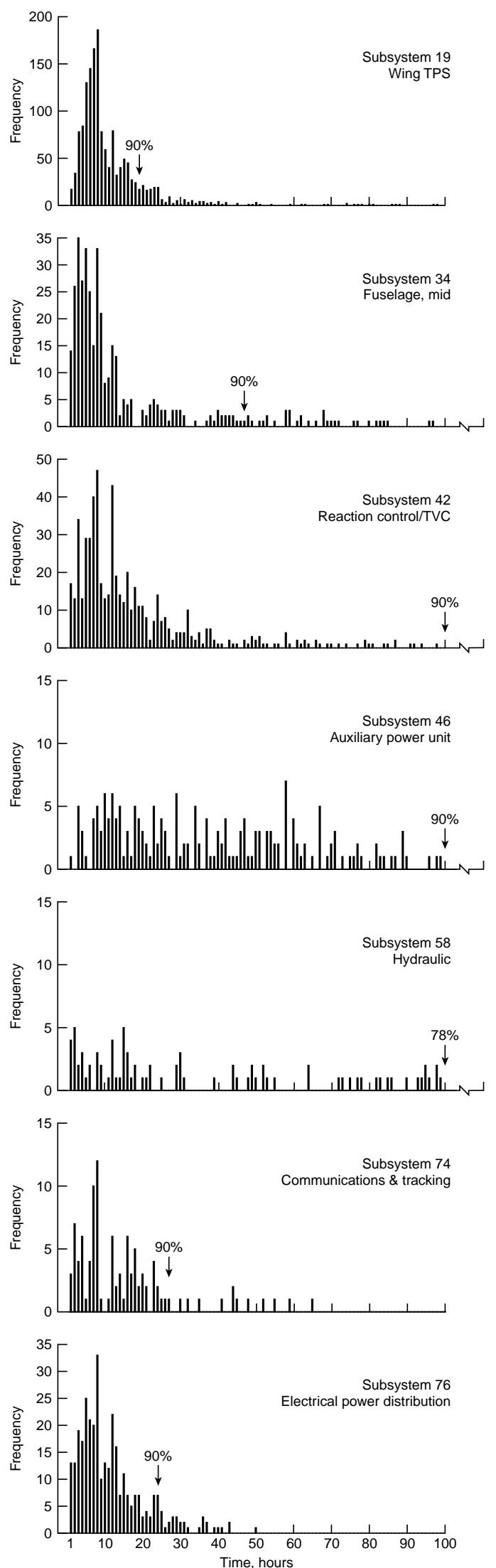

Figure 3. Scheduled mean task time frequency distribution. 
Table 3. Results of Curve Fitting for Scheduled Task Times.

\begin{tabular}{lcccccccc}
\hline \hline Subsystem & $\mathrm{n}$ & $\begin{array}{c}\text { Sample } \\
\text { mean }\end{array}$ & $\begin{array}{c}\text { Sample } \\
\text { std dev }\end{array}$ & $\begin{array}{c}\mathrm{R}^{2} \\
\text { exponential }\end{array}$ & $\begin{array}{c}\mathrm{R}^{2} \\
\text { Weibull }\end{array}$ & $\begin{array}{c}\mathrm{R}^{2} \\
\text { normal }\end{array}$ & $\begin{array}{c}\mathrm{R}^{2} \\
\text { lognormal }\end{array}$ & $\begin{array}{c}\text { Best } \\
\text { fit }\end{array}$ \\
\hline Wing TPS & 380 & 17.06 & 23.83 & 62 & 86 & 44 & 88 & Log/Weib \\
Fuselage, mid & 388 & 16.25 & 23.83 & 88 & 94 & 66 & 95 & Log/Weib \\
RCS & 380 & 40.37 & 18.63 & 55 & 93 & 47 & 96 & Log/Weib \\
APU & 211 & 47.33 & 42.05 & 98 & 94 & 84 & 87 & Exp/Weib \\
Hydraulics & 104 & 51.82 & 46.56 & 90 & 92 & 89 & 80 & Weib/Exp \\
Comm/Tracking & 339 & 13.22 & 14.69 & 96 & 98.5 & 72 & 94 & Weib/Exp \\
Electrical & 333 & 11.35 & 9.30 & 98 & 97 & 86 & 90 & Exp/Weib \\
\hline \hline
\end{tabular}

Table 4. Results of Curve Fitting for Unscheduled Repair Times.

\begin{tabular}{lcccccccc}
\hline \hline Subsystem & $\mathrm{n}$ & $\begin{array}{c}\text { Sample } \\
\text { mean }\end{array}$ & $\begin{array}{c}\text { Sample } \\
\text { std dev }\end{array}$ & $\begin{array}{c}\mathrm{R}^{2} \\
\text { exponential }\end{array}$ & $\begin{array}{c}\mathrm{R}^{2} \\
\text { Weibull }\end{array}$ & $\begin{array}{c}\mathrm{R}^{2} \\
\text { normal }\end{array}$ & $\begin{array}{c}\mathrm{R}^{2} \\
\text { lognormal }\end{array}$ & $\begin{array}{c}\text { Best } \\
\text { fit }\end{array}$ \\
\hline Wing TPS & 137 & 15.36 & 19.80 & 86 & 96 & 63 & 96 & Log/Weib \\
Fuselage, mid & 119 & 16.89 & 34.87 & 34 & 97 & 39 & 96 & Weib/Log \\
RCS & 37 & 16.50 & 24.92 & 65 & 96 & 55 & 94 & Weib/Log \\
APU & 79 & 20.75 & 25.82 & 86 & 97 & 70 & 91 & Weib/Log \\
Hydraulics & 197 & 13.00 & 14.11 & 96 & 99 & 74 & 94 & Weib/Exp \\
Comm/Tracking & 43 & 9.86 & 7.57 & 96 & 97 & 91 & 96 & Weib/Log \\
Electrical & 63 & 17.30 & 19.55 & 96 & 95 & 74 & 99 & Log/Exp \\
\hline \hline
\end{tabular}

tion of their task time requirements. The results are presented for the scheduled support in Figures 2 and 3 and Table 3, and for the unscheduled in Figure 4 and Table 4.

\section{Scheduled}

For scheduled support, the mean task times by mission are shown in Figure 2 for the representative subsystems. These are presented as a function of the STS flights plotted in order of their mission sequence. For most of these systems, no task time trend could be observed. A decreasing trend might be expected for repetitive tasks such as these. The reason this is not observed could be attributed to several factors. It may be that any learning that takes place is offset by increasing difficulties in performing the task due to aging equipment, both airborne and ground. Also the fixed flight schedule, limiting the fleet to seven flights per year places no incentive on reducing the time required for a task as long as it is within the time allotted to support the flight rate. And finally, the nature of the task may be changing over time with the procedures being redefined to accommodate new information. The assumption is made that the support task functions are consistently the same between flights. The mean task times show mechanical type systems such as the Hydraulics, Auxilary Power Unit (APU) and Reaction Control System (RCS) require significantly longer work times than do the avionics, electrical and Thermal Protection System (TPS).

The task time frequency distributions are shown in Figure 3 for each system. Curve fitting the data, most systems display a lognormal or Weibull distribution for the scheduled task times. These results are summarized in table 3 for samples from each representative subsystem. The APU and Electrical subsystems also display a very good fit to an exponential distribution. The results shown in Figure 3 also illustrate the longer work times required of the mechanical systems with larger means and standard deviations than the other systems. These distributions are shown for up to 100 hours of time to complete a task. Half of the tasks are completed in a single work shift for the TPS, Mid Fuselage, Communications \& Tracking and Electrical Power Distribution subsystems. All except the Hydraulics and the RCS systems complete 90 percent of the tasks within that period. The Hydraulics system completes only 78 percent of the tasks within that time. The multishift tasks appear to be characteristic of the scheduled support for these systems.

\section{Unscheduled}

The number of maintenance actions and the distribution of task times are shown for the unscheduled repair tasks in Figure 4. Most of these systems can complete 

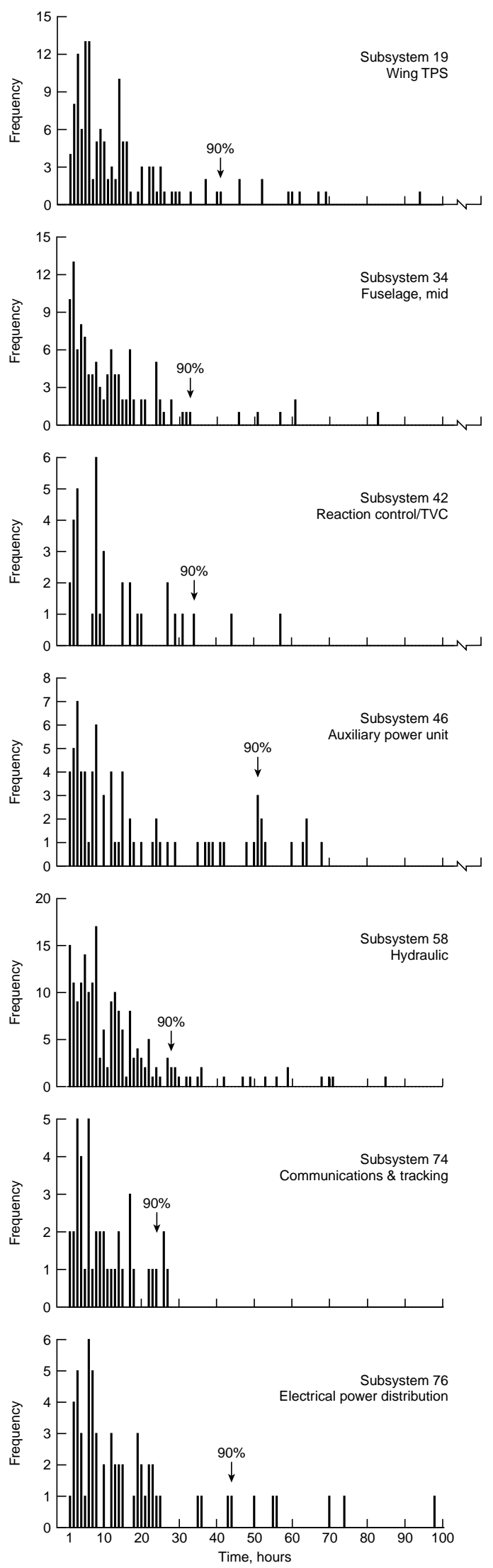

Figure 4. Unscheduled repair time frequency distribution. half of the task within a single shift and all are 90 percent complete within 7 shifts (56 hours). The probability distribution for the subsystem repair time can be modeled accurately, in most cases, as either a Weibull or lognormal distribution with the parameter values as shown in Table 4. The fact that either distribution may be used in all but the hydraulics or electrical subsystem is not surprising since both distributions can take on similar shapes. Historically the lognormal distribution has been used to model repair times. The repair time of hydraulics and electrical subsystems may also be modeled as an exponential distribution. The use of the exponential distribution is further supported by the fact that the sample mean and standard deviation are "close" to each other. Theoretically they have the same value. Since the exponential distribution is also a special case of the Weibull (when the shape parameter equals one), then the fact that the Weibull is also a good fit is expected.

In order to identify a distribution for the number of failures per mission, the chi-square goodness-of-fit test was applied to three discrete distributions: the binomial, Poisson, and negative binomial. In all cases, the negative binomial was the only acceptable fit with the parameter values as shown in Table 5. However, for the Wing TPS, the large chi-square value indicates the fit was marginal. This result is consistent with aircraft modeling in which the negative binomial has been used to represent the number of demands (i.e. failures) per 100 flying hours. The negative binomial has a variance-tomean ratio greater than one (the Poisson equals one and the binomial is less than one). Aircraft data and the Shuttle data for the seven subsystems analyzed have shown a variance-to-mean ratio greater than one. Therefore, this result is not surprising.

In simulating a space transportation system, the above results can be used to randomly determine the number of unscheduled maintenance actions to be expected for each subsystem following a mission. Then, by simulating each maintenance action, a random draw from the fitted repair time distribution will be made to determine a simulated repair time. With the proper identification of crew sizes, and by constraining the number of crews available each shift, a realistic vehicle turntime and mission rate can then be obtained from the simulation model.

Subsystem reliability, like component maintenance reliability, is based on the amount of time or cycles that the system successfully functions over its operating life. Representative operating hours were developed as a part of the study to be used for defining the maintenance fail- 
Table 5. Results of Curve Fitting for Number of Failures per Mission.

\begin{tabular}{lcccccr}
\hline \hline Subsystem & Best & Chi-sq & Parameter & Parameter & & \multicolumn{2}{c}{ Std } \\
stat & fit & s & p & Mean & \multicolumn{1}{c}{ dev } \\
\hline Wing TPS & Neg Bin & 41.745 & 4 & .01 & 375.0 & 178.60 \\
Fuselage, mid & Neg Bin & 1.753 & 5 & .26 & 14.2 & 7.16 \\
RCS & Neg Bin & 2.747 & 5 & .18 & 21.85 & 10.80 \\
APU & Neg Bin & 2.590 & 3 & .14 & 18.0 & 10.14 \\
Hydraulics & Neg Bin & 2.789 & 7 & .21 & 26.7 & 10.85 \\
Comm/Tracking & Neg Bin & 1.106 & 2 & .19 & 8.75 & 6.46 \\
Electrical & Neg Bin & 1.066 & 4 & .36 & 7.0 & 4.28 \\
\hline \hline
\end{tabular}

Negative binomial density function: $f(x)=\left(\begin{array}{c}s+x-1 \\ x\end{array}\right) p^{x}(1-p)^{x} ; x=0,1,2,3 \ldots$

Table 6. Power-on Values.

\begin{tabular}{clcc}
\hline \hline & \multicolumn{1}{c}{ Subsystem } & GPOT, & FPOT, \\
& \multicolumn{1}{c}{ Description } & hrs \\
\hline 5 & Purge, vent, and drain & 8 & 1 \\
37 & Payload bay doors & 3 & 1 \\
38 & Fuselage PV\&D & 8 & 0 \\
41 & Main propulsion & 24 & 1 \\
42 & Reaction control/TV & 37 & FPOT \\
45 & Electrical power generation & 6 & FPOT \\
46 & Auxiliary power unit & 24 & 4 \\
55 & Pyrotechnics and range safety & 5 & 1 \\
57 & Aero surface control & 4 & 4 \\
58 & Hydraulics & 12 & 4 \\
59 & Actuation mechanisms & 14 & 4 \\
60 & ECLS (general) (see also & & \\
& dependency desc for payload) & 14 & FPOT \\
61 & Atmospheric revitalization & 100 & FPOT \\
62 & Life support & 17 & FPOT \\
63 & Active thermal control & 100 & FPOT \\
64 & Airlock support & 14 & 0 \\
70 & Avionics (general) (see also & & \\
& dependency desc for payload) & 100 & FPOT \\
71 & Guidance and navigation & 14 & FPOT \\
72 & Data processing & 100 & FPOT \\
73 & Displays and controls & 100 & FPOT \\
74 & Communications and tracking & 14 & FPOT \\
75 & Instrumentation (operational) & 100 & FPOT \\
76 & Electrical power distribution & 100 & FPOT \\
77 & Interconnecting wiring & 100 & FPOT \\
79 & Flight control & 12 & 1 \\
91 & Primary avionics system software & 100 & FPOT \\
96 & Gent controller supervisor software & FPOT \\
\hline \hline
\end{tabular}

ure rate. The mean Ground Power On Time (GPOT) and Flight Power On Time (FPOT) for the 20 missions analyzed is 1,450 and 264 hours respectively, as summarized in Table 2. For those systems where the power-on time was considered relevant to maintenance reliability of the system, the percentage of operating hours when the systems were being serviced on the ground were developed. This was done by Lockheed in consultation with the Test Project Engineers and are shown in Table 6 for each subsystem. Also, the amount of the mission time is defined along with specific operating hours for subsystems that were not dependent on mission length. This information can then be used to compute the mean time between maintenance actions (MTBMA) required for these subsystems. These rates are not computed here, leaving to the analyst to decide whether the operating hours or some other parameter such as cycles is the appropriate reliability metric for their study.

A comparison of both scheduled and unscheduled work leads one to several characteristics of this support. In general, the number of scheduled tasks will be equal to or greater than the number of unscheduled tasks. Also, for the representative cases, scheduled tasks times for the mechanical systems are more than twice the mean unscheduled repair times for those same systems, and for Hydraulics it is four times the mean repair time. All other systems have consistent task times whether for scheduled or unscheduled work. Task time distributions for both appear to be primarily Weibull or lognormal.

\section{SUMMARY/CONCLUSIONS}

The Shuttle support data collection system at KSC was established for the purpose of accounting for system and element processing requirements. Although not established to support R\&M data analysis, much of the 
information is relevant to reusable launch vehicles and was used to form a Shuttle R\&M data base. This paper is a preliminary report on the analysis of that information. The data is used to characterize the R\&M support for subsystems on future reusable launch vehicles on the assumption that it is representative of the support required for each subsystem. The results presented provide benchmark values of repair rates, manpower and task times that can be used by the analyst for guidance in allocating both reliability and maintainability of new systems based on the flight experience of the Shuttle Orbiter. The results of analysis for shape distribution are also presented for seven representative types of support including thermal protection, mechanical systems, avionics, electrical distribution and power. These results represent the first analysis of maintenance support for the Shuttle subsystems based on previously unavailable historical manpower records.

\section{REFERENCES}

1. Fisher, R., Drake, W., Delfausse, J., Clark, A., and Buchanan, A., "The Logistics Composite Model: an overall view." The Rand Corporation, RM-5544-PR., Santa Monica, CA. May, 1968.

2. Schlagheck, R. A. and J. K. Byers. "Simulating The Operations of the Reusable Shuttle Space Vehicle." Proceedings of the 1971 Summer Computer Simulation Conference, pp. 192-152, July 1971.

3. Morris, W. D., T. A. Talay and D. G. Eide. "Operations Simulation for the Design of a Future Space Transportation System." Presented at the AIAA 21st Aerospace Sciences Meeting, paper no. 83-0140, January 1983.

4. Morris, W. D. and N. H. White. "A Space Transportation System Operations Model." NASA TM 100481, December, 1987.

5 Huseonica, W. F., private communication, "Shuttle II Data Base Development," Teledyne Brown Engineering, SC7490, Huntsville, AL, July 1987.

6 Ebeling, C. E., private communication, "The Determination of Operational and Support Requirements and Costs During The Conceptual Design of Space Systems," Grant No. NAG1-1-1327, University of Dayton, August, 1992.
7. Ebeling, C. E., "Parametric Estimation of R\&M Parameters During the Conceptual Design of Space Vehicles." IEEE 1992 National Aerospace and Electronics Conference, Vol 3, Univ. of Dayton, Dayton $\mathrm{OH}$, pp. 955-959

8. Morris, W. D., N. H. White, W. T. Davis and C. E. Ebeling, "Defining Support Requirements During Conceptual Design of Reusable Launch Vehicles," Presented at the AIAA 1995 Space Programs and Technologies Conference, September 26-28, 1995, paper No. AIAA-95-3619.

9. Weber, T. F., "Reliability and Maintainability in Space Systems Design." Presented at the Aerospace Design Conference, Paper no. 93-1025, Feb 16-19, 1993.

10. Fleming, B. W., private communication, "Launch Vehicle Maintenance Analysis," Martin Marietta Manned Space Systems, NAS1-18230, Task 18, NASA Langley Research Center, Hampton, VA, November 1992.

11. Eshleman W., private communication, "Available Shuttle Systems Data Base Identification and Pathfinder Data Search" Lockheed Martin, NASA MSFC, Huntsville AL, May 31,1995.

12. Anderson, J. M., private communication, "Maintenance Trend Analysis Report," United Space Alliance, Logistics Directorate, NAS10-10900, DRD046.

13. Wise, H. G., private communication, "Launch +15 Day Shuttle Trend Analysis Report Plus," United Space Alliance.

14. Harrison, R.M., private communication, "Orbiter Reliability Centered Maintenance Report," Flight Projects Branch, Kennedy Space Center, NASA

15. Seymour, V. M. and Ingoldsby, K. A., private communication, "Operation \& Support Database and Analysis," Lockheed Martin Manned Space Systems, NAS8-36200, TD-926, NASA Langley Research Center, Hampton, VA, July 1996.

16. Space Shuttle Subsystem Codes, NASA, Johnson Space Center, NSTS 08170, Revision C, March 4, 1994. 